\title{
Spirometric testing on World COPD Day
}

This article was published in the following Dove Press journal:

International Journal of COPD

I0 February 201I

Number of times this article has been viewed

\section{Tanja Grzetic-Romcevic' \\ Boris Devcic ${ }^{2}$ \\ Silvana Sonc' \\ 'Department of Pneumonology, Hospital Sezana, Sezana, Slovenia; ${ }^{2}$ Clinical Department of Respiratory Diseases and Allergy, University Clinical Center, Ljubljana, Slovenia}

Correspondence: Tanja Grzetic-Romcevic Department of Pneumonology, Hospital Sezana, Cankarjeva 4, 6210 Sezana, Slovenia

Tel +38640230105

Fax+38657074019

Email dr.romcevic@gmail.com
Background: To determine the importance of spirometric testing for early detection of chronic obstructive pulmonary disease (COPD).

Methods: Spirometric testing has been performed annually on World COPD Day in Sezana from 2003. Sezana is in a semiurban region of Slovenia, with 12,000 inhabitants. The investigation was performed between January 2003 and December 2008. In total, 770 persons were enrolled (414 females and 356 males). The participants were recruited by mass media appeals. Smokers aged $\geq 40$ years with a smoking history of $\geq 10$ pack-years were invited to visit the local chest clinic. The participants completed a questionnaire and had spirometry performed. Subjects with a postbronchodilator forced expiratory volume in one second/forced vital capacity $<0.70$ were defined as having COPD, according to the Global Initiative for Chronic Obstructive Lung Disease guidelines.

Results: We identified that $16.2 \%$ of subjects had impaired lung function. Of these, $10.2 \%$ had an obstructive pattern of ventilatory impairment and $6 \%$ had a restrictive pattern. We identified 79 individuals with COPD. Subjects with COPD were $>70$ years in $40.5 \%$ in cases. The majority of individuals with COPD were men (74.6\%), and 90\% were smokers. COPD was mild in $52 \%$ of subjects, moderate in $34 \%$, and severe in $14 \%$. The majority of subjects had a milder stage of the disease, and $92 \%$ of those with COPD (72/79) had not been recognized to have COPD previously.

Conclusion: These results suggest that spirometry testing could detect patients with COPD in the earlier stages of the disease.

Keywords: chronic obstructive pulmonary disease, epidemiology, smoking, spirometry

\section{Introduction}

COPD is one of the leading causes of morbidity and mortality in industrialized countries worldwide, and is emerging as being increasingly important in developing countries. ${ }^{1-4}$ Assuming that current trends in mortality continue, COPD will move from being the sixth leading cause of death worldwide in 1990 to the third in $2020 .{ }^{5}$ Epidemiological studies in Europe have demonstrated that COPD affects about $9 \%$ of the adult population, mostly smokers. ${ }^{6,7}$ The disease is poorly recognizable by both patients and health care providers, especially in the earlier stages. ${ }^{8,9}$ Population-based surveys that have used spirometry have documented the underdiagnosis of COPD. ${ }^{9-12}$ For example, a Korean survey found that $17.2 \%$ of Korean adults over the age of 45 years have mild COPD and only a minority had been diagnosed. ${ }^{11}$ In the PLATINO study, $88.7 \%$ of COPD cases had not been previously diagnosed. ${ }^{12}$ Underdiagnosis was related to 
severity of COPD, because milder disease is missed more often than severe disease..$^{11,12}$

\section{Materials and methods Study design and population}

This study was conducted at Sezana Hospital in Sezana, a town in the southwestern part of Slovenia. The aim was to evaluate the usefulness of spirometric testing for early detection of airflow obstruction. The testing was first started on World COPD Day 2003, and then we continued to perform free spirometric testing annually on this day. Our target population was the inhabitants of Sezana, current and former smokers aged $\geq 40$ years, with a smoking history of $\geq 10$ pack-years. Inclusion criteria were aged above 40 years and a history of smoking ( $>10$ pack-years), exclusion criteria were the presence of any other pulmonary disease and comorbid conditions that preclude use of spirometry. Although the target population was defined as smokers aged $\geq 40$ years, it was decided that never-smokers who were concerned about their lung health would be included in the project.

The participants were invited by mass media appeals (advertisements on TV, radio, newspapers) and billboards displayed in public places. Primary care physicians were asked to encourage eligible patients to participate in the project. The study was approved by the local hospital ethics committee, and all participants gave their written informed consent. Spirometric testing was conducted in two parts. The first part was conducted from 2004 to 2006, and the second part was conducted from 2006 to 2008 .

\section{Questionnaire data}

All subjects completed a questionnaire seeking demographic and anthropometric data, history of smoking, cough, expectoration, dyspnea, and allergies.

\section{Tests}

Spirometry was performed by an experienced certified technician at the lung function laboratory of the Hospital Sezana. Forced expiratory volume in one second $\left(\mathrm{FEV}_{1}\right)$ and forced vital capacity (FVC) were recorded according to American Thoracic Society recommendations ${ }^{13}$ using a flow screen Jaegar spirometer (Jaeger, Wuertzburg, Germany), with participants in a seated position. This spirometer fulfils the American Thoracic Society criteria. ${ }^{13}$ After initial spirometry, a bronchodilatory test was performed with inhalation of salbutamol (GlaxoSmithKline, Montrose, United
Kingdom) $100 \mu \mathrm{g}$ four puffs to all subjects, administered via a metered-dose inhaler with a spacer. After an additional 15 minutes, postbronchodilator spirometry was performed. Two investigators independently assessed the quality of the flow-volume curves according to the criteria of the American Thoracic Society. ${ }^{13}$ To be deemed usable for the analysis, spirometry had to meet American Thoracic Society acceptability and reproducibility criteria.

\section{Definitions}

In accordance with the Global Initiative for Chronic Obstructive Lung Disease (GOLD) guidelines, irreversible airflow obstruction was defined as a postbronchodilator $\mathrm{FEV}_{1} / \mathrm{FVC}$ ratio of $<0.70$, which corresponds to GOLD Stage I. ${ }^{14,15}$ Airflow obstruction was classified according to the GOLD criteria. Severity of COPD is distinguished in four stages:

- Mild (GOLD Stage I) $\mathrm{FEV}_{1} / \mathrm{FVC}$ ratio $<0.70$ and $\mathrm{FEV}_{1}>80 \%$ predicted

- Moderate (GOLD Stage II) $\mathrm{FEV}_{1} / \mathrm{FVC}$ ratio $<0.70$ and $\mathrm{FEV}_{1} 50 \%-80 \%$ predicted

- Severe (GOLD Stage III): $\mathrm{FEV}_{1} / \mathrm{FVC}$ ratio $<0.70$ and $\mathrm{FEV}_{1} 30 \%-50 \%$ predicted

- Very severe (GOLD Stage IV): $\mathrm{FEV}_{1} / \mathrm{FVC}$ ratio $<0.70$ and $\mathrm{FEV}_{1}<30 \%$ predicted or $\mathrm{FEV}_{1}<50 \%$ with signs of chronic respiratory failure.

Predicted values for $\mathrm{FEV}_{1}$ and $\mathrm{FVC}$ were computed using the regression equations of the European Coal and Steel Community approved by the European Respiratory Society. ${ }^{16}$ The values for $\mathrm{FEV}_{1} / \mathrm{FVC}$ and $\mathrm{FEV}_{1}$ were postbronchodilator, and were expressed as a percentage of predicted. The GOLD definition of reversibility was used, ie, $\mathrm{FEV}_{1}$ increase of $200 \mathrm{~mL}$ and $12 \%$ improvement above baseline $\mathrm{FEV}_{1}$ following the administration of bronchodilator. Doctordiagnosed COPD was defined as self-reported physician's diagnosis of chronic bronchitis, emphysema, or COPD. The number of pack-years of cigarette smoking was defined as the average number of cigarettes smoked per day divided by 20 (ie, packs per day) times the duration of smoking in years. The participants identified to have COPD were sent for further investigation and treatment at the Department of Pneumonology, Sezana Hospital.

\section{Data presentation and statistics}

Continuous variables are expressed as the mean ( \pm standard deviation) and prevalence rates as crude and standardized gender-adjusted values. The Student's $t$-test was used to compare continuous variables, and Chi-square values were 
used for testing between groups of frequencies. $P<0.05$ was considered statistically significant.

\section{Results}

Of the 1254 individuals contacted, 110 were not eligible on the basis of age. Of the remaining 1144 eligible participants, $770(67 \%)$ completed the questionnaire data, and had spirometry findings that met American Thoracic Society quality control criteria. These individuals constituted the final sample for the analysis. In total, 329 persons (29\%) did not complete the questionnaire data, and 45 individuals (4\%) completed the questionnaire data but had unusable spirometry (see Figure 1).

The final sample consisted of 356 males (46\%) and 414 females $(54 \%)$. The average age was $59.6 \pm 14.8$ years, for females $60 \pm 13.6$ years, and for males $58.2 \pm 16.0$ years. One quarter of the participants were aged $40-50$ years, and almost half of them were aged 50-70 years. The remaining individuals were older than 70 years (see Table 1).

Two-hundred and seventy-eight subjects (36.1\%) were current smokers, 178 (23.1\%) were former smokers, and 314 (40.8\%) were never-smokers. Significantly $(P<0.001)$ more males $(201,56.5 \%)$ than females $(77,18.6 \%)$ were current smokers. The opposite was found among former smokers, in that 57 males and 121 females were former smokers $(16.0 \%$ versus $29.2 \%, P<0.001)$. Males had an average smoking history of $26.1 \pm 2$ pack-years and females $16.5 \pm 4$ pack-years. Smoking intensity above 15 pack-years was reported by 148 (52.2\%) current smokers (see Table 2).

The results of spirometry were within normal limits for 645 subjects $(83.8 \%)$ and a pattern of ventilatory impairment was found in 125 subjects (16.2\%). Among these, 79 subjects (10.2\%) had airflow limitation (obstruction) and 46 subjects $(6.0 \%)$ had a restrictive pattern of ventilatory impairment (see Table 3 ). Table 4 reports spirometry in the study participants.

COPD was diagnosed in 79 subjects $(10.2 \%)$. Of these, 41 persons $(52 \%)$ had the mild form (GOLD I), 27 persons (34\%) had the moderate form (GOLD II), and 11 (14\%) had the severe form of the disease. None had the severe stage of disease (GOLD IV). The majority of patients had mild stage of the disease (GOLD I). Fifty-nine patients with COPD (74.6\%) were men (see Figure 2).

The prevalence of airways obstruction increased with age, from six patients $(7.6 \%)$ in the fourth decade to 33 patients $(40.5 \%)$ aged 70 years or more. The average age of the individuals with COPD was 65 years \pm 4.0 (Figure 3 ).

Among patients with COPD, 54 patients were current smokers $(68.4 \%), 17$ patients were former smokers $(21.5 \%)$, and eight patients were never-smokers (10.1\%). The majority of the patients with COPD $(80.3 \%)$ reported $>15$ pack-years of smoking. A higher proportion of male patients with COPD were current smokers, compared with female patients

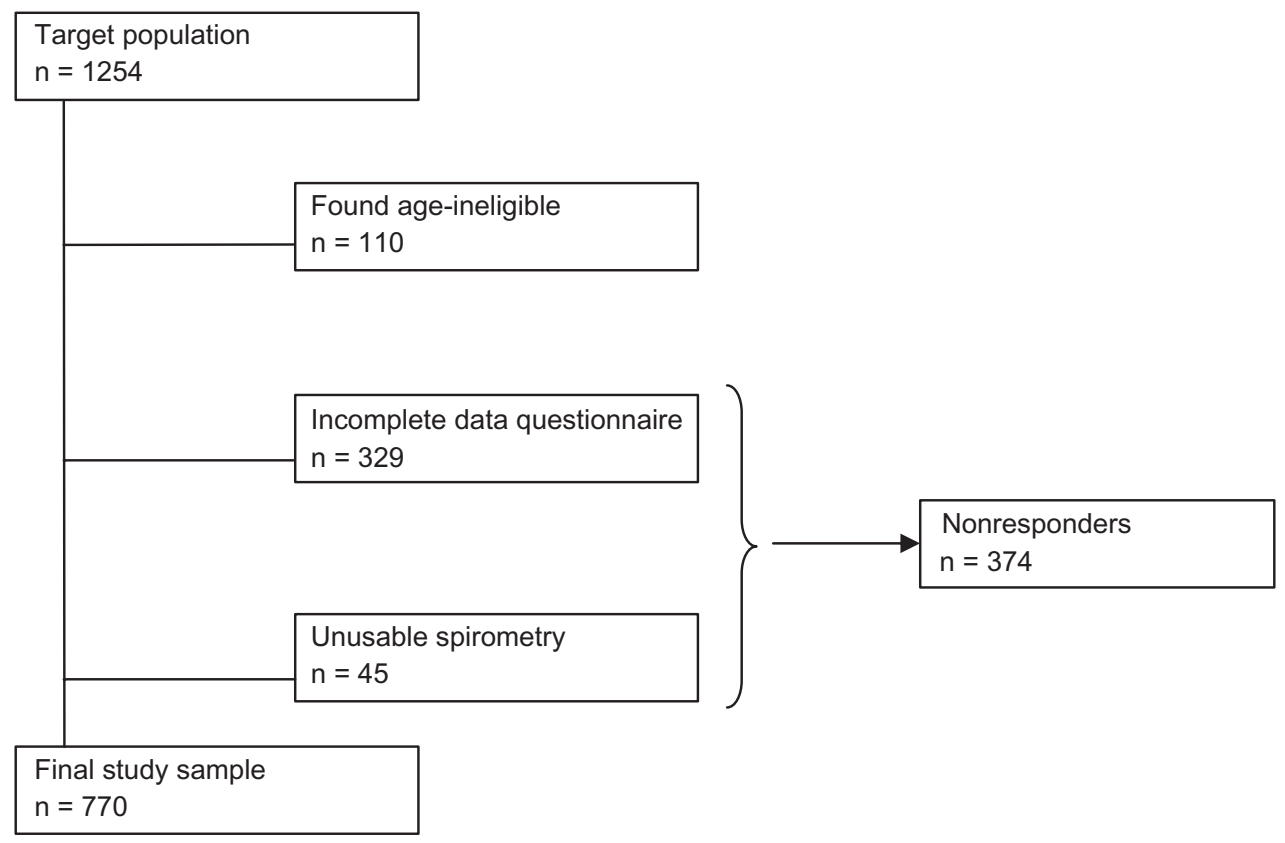

Figure I Flow diagram of the study population. 
Table I Demographic characteristics of the study sample

\begin{tabular}{llll}
\hline Age/years & $\begin{array}{l}\text { Male } \\
\mathbf{n}(\%)\end{array}$ & $\begin{array}{l}\text { Female } \\
\mathbf{n}(\%)\end{array}$ & $\begin{array}{l}\text { Total } \\
\mathbf{n}(\%)\end{array}$ \\
\hline $40-49$ & $116(32.5)$ & $81(19.6)$ & $197(25.5)$ \\
$50-59$ & $59(16.5)$ & $93(22.4)$ & $152(20.0)$ \\
$60-69$ & $75(21.0)$ & $122(29.5)$ & $197(25.5)$ \\
$70+$ & $106(30.0)$ & $118(28.5)$ & $224(29.0)$ \\
\hline
\end{tabular}

Notes: Chi-square value $=85,33 ; \mathrm{df}=3 ; P=0.01$. There is a statistically significant difference between male and female patients.

(71.2\% versus $60 \%, P<0.001)$. Gender differences also existed in terms of mean pack-years. Men were more intensive smokers than women (36 \pm 10 pack-years versus $19 \pm 10$ pack-years, $P<0.001$, Figure 4 ).

The prevalence of COPD among females was $4.8 \%$ and was $16.6 \%$ among males. The prevalence of COPD in current smokers was $19.4 \%, 9.6 \%$ in former smokers, and $2.6 \%$ in never-smokers. Seventy-three of 79 with COPD had not been recognized prior to this survey. We identified $92 \%$ of patients with COPD, but previous diagnosis of COPD by a doctor was reported by only six patients $(8 \%)$.

\section{Discussion}

The key findings of this survey are that $9.5 \%$ of the participants had previously undetected COPD, and over half of the individuals identified to have COPD (52\%) had a mild form of this disease. However, this study does have several limitations. One is the smallness of the sample size and that the recruitment was based on voluntary participation, so was not representative of the population of Slovenia. The other limitation is that the use of the fixed ratio $\left(\mathrm{FEV}_{1} / \mathrm{FVC}<0.7\right)$ as the cutoff point for airflow obstruction, as recommended by GOLD, has the potential for misclassification at older ages. The present GOLD guidelines endorse the use of the fixed ratio, while recognizing that there is potential for misclassification.

A meta-analysis of epidemiological investigations, based on spirometry testing, has shown a COPD prevalence in the developed world of $8.9 \%(7.4 \%-10.7 \%) .{ }^{17}$ The COPD prevalence in our cohort $(10.2 \%)$ is consistent with the

Table 2 Smoking status of the study participants

\begin{tabular}{llll}
\hline Smokers & Male & Female & Total \\
& n (\%) & n (\%) & n (\%) \\
\hline Current & $20 \mathrm{I}(56.5)$ & $77(18.6)$ & $278(36.1)$ \\
Former & $57(16.0)$ & $121(29.2)$ & $178(23.1)$ \\
Never & $98(27.5)$ & $216(52.2)$ & $314(40.8)$ \\
\hline
\end{tabular}

Notes: Chi-square value $=118,97 ; \mathrm{df}=2 ; P=0.01$. There is a statistically significant difference between male and female patients.
Table 3 Pulmonary function in the study participants

\begin{tabular}{|c|c|c|c|c|c|c|c|c|}
\hline \multirow{2}{*}{$\begin{array}{l}\text { Pulmonary } \\
\text { function }\end{array}$} & \multicolumn{2}{|l|}{ Male } & \multicolumn{2}{|c|}{ Female } & \multicolumn{2}{|c|}{ Total } & \multirow[t]{2}{*}{$t$-value } & \multirow[t]{2}{*}{$P$ value } \\
\hline & $\bar{M}$ & SD & $\bar{M}$ & SD & $\bar{M}$ & SD & & \\
\hline $\mathrm{FEV}_{1}$ (L) & 3.30 & 1.2 & 3.1 & I & 3.22 & 1.12 & 2.281 & $0.023 *$ \\
\hline $\begin{array}{l}\mathrm{FEV}_{1} \text { (\% of } \\
\text { predicted) }\end{array}$ & 0.99 & 17.2 & 0.97 & 19.8 & 0.98 & 18.63 & 1.651 & 0.099 \\
\hline FVC (L) & 4.40 & 2.0 & 4.09 & 1.9 & 4.25 & 2.01 & 2.163 & $0.031 *$ \\
\hline $\begin{array}{l}\mathrm{FEV}_{1} / \mathrm{FVC} \\
\text { ratio }\end{array}$ & 75.16 & 7.4 & 75.6 & 10.0 & 75.4 & 8.91 & -0.725 & 0.468 \\
\hline
\end{tabular}

Note: *Statistically significant difference.

Abbreviations: $\mathrm{FEV}_{\text {, }}$, forced expiratory volume in one second; FVC, forced vital capacity; SD, standard deviation.

reported COPD prevalence in other epidemiological surveys worldwide, ${ }^{17-22}$ although the comparison of prevalence rates for COPD is very difficult because the studies have used different methodologies. ${ }^{18-24}$

Several candidate populations for a screening strategy by means of spirometry have been advocated in the available literature..$^{25-29}$ In our survey of spirometric testing, we used the strategy of Zielinski and Bednarek for the target population, the manner of recruiting the participants, the type of spirometer, regression equations for computing $\mathrm{FEV}_{1}$ and $\mathrm{FVC}$, and the criteria for defining COPD. ${ }^{25}$ The prevalence of COPD in current smokers in this study was $19.4 \%$, which is in accordance with other international epidemiological studies..$^{10,30}$

The gender-standardized COPD prevalence in our survey was $15.7 \%$ for men and $5.5 \%$ for woman, which can be explained with the difference in smoking intensity. Given the increasing smoking rate among women in recent decades, one may expect that the prevalence of airflow obstruction in female smokers will rise in the near future. ${ }^{31}$

Although tobacco smoking is the main risk factor for COPD, other factors could be involved in its development. ${ }^{26}$ However, the prevalence of COPD in our survey among never-smokers was low at $2.6 \%$. Some studies that have detected the prevalence of COPD included never-smokers, in which case the prevalence was $20.4 \%-30 \%,{ }^{11,32}$ and other studies excluded never-smokers. ${ }^{12}$

Our investigation shows that the prevalence of airway obstruction increased with age, with the highest prevalence

Table 4 Spirometry in the study participants

\begin{tabular}{llll}
\hline Spirometry & $\begin{array}{l}\text { Male } \\
\text { n (\%) }\end{array}$ & $\begin{array}{l}\text { Female } \\
\text { n (\%) }\end{array}$ & $\begin{array}{l}\text { Total } \\
\text { n (\%) }\end{array}$ \\
\hline Normal & $283(79.4)$ & $362(87.4)$ & $645(83.8)$ \\
Airflow limitation & $56(15.7)$ & $23(5.5)$ & $79(10.2)$ \\
Restriction & $17(14.9)$ & $29(7.1)$ & $46(6.0)$ \\
\hline
\end{tabular}

Notes: Chi-square value $=22,35 ; \mathrm{df}=2 ; P=0.01$. There is a statistically significant difference between male and female patients. 


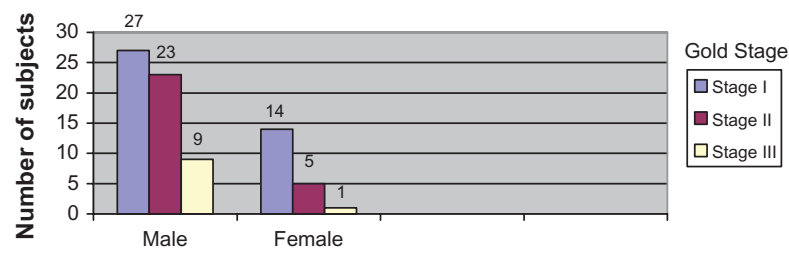

Figure 2 Classification of chronic obstructive pulmonary disease patients according to GOLD stage.

Abbreviation: GOLD, Global Initiative for Chronic Obstructive Lung Disease.

seen in men and women $>70$ years of age, which is similar to data obtained by other investigators. ${ }^{11,12}$ This fact must be considered with caution, because we and other investigators have used fixed ratio $\mathrm{FEV}_{1} / \mathrm{FVC}<0.7$ as the cutoff point for airflow obstruction.

In the present study, one-third of patients (31.6\%) with COPD were aged 40-60 years, indicating the importance of the disease in the working population. ${ }^{33}$ Tzanakis et al detected nearly $40 \%$ of individuals with COPD aged 40-60 years. ${ }^{34}$

Although the proportion of subjects younger than 50 years with COPD is obviously lower than that of older individuals, we detected $7.6 \%$ such individuals. These rates are of interest because they represent a cohort of patients with a presumably long life expectancy, and a considerable contribution to the burden of the disease. ${ }^{35}$

An important finding of our study is that there was a huge gap between physician diagnosis of COPD and the presence of airflow obstruction defined by spirometry. Ninety-two percent of our subjects did not report a prior physician diagnosis of COPD. Our participants were recruited so that they were self-selected and came to our hospital on a voluntary basis and were included in this study. Therefore, this rate (92\%) most likely does not accurately represent the actual rate of undetected COPD in the target population, and did not provide population-based prevalence estimates. This discrepancy between physician diagnosis and obstruction defined by spirometry has also been reported by other investigators. ${ }^{32}$

Fourteen percent of our patients without a prior diagnosis of COPD had severe stages of the disease. Mannino et al

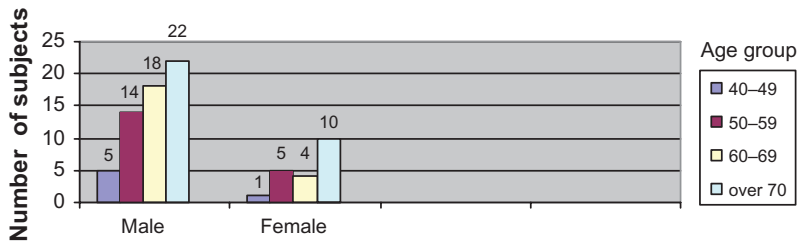

Figure 3 Classification of patients with chronic obstructive pulmonary disease by age group.

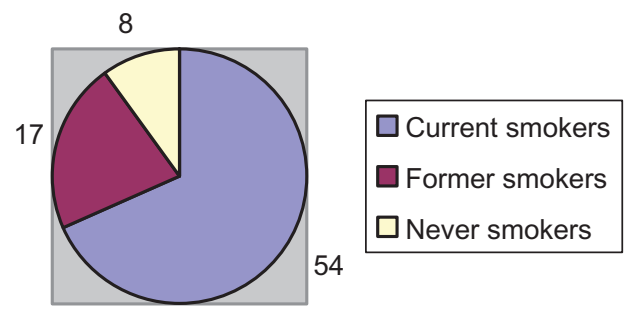

Figure 4 Smoking status among patients with chronic obstructive pulmonary disease.

reported that, among their participants, $63.3 \%$ of COPD cases was detected for the first time, and $44 \%$ of the patients who were detected had severe disease according to the GOLD classification. ${ }^{10}$ One of the reasons for the late detection of the disease is that the patients did not recognize the symptoms of the illness early enough. ${ }^{36}$ In order to improve early detection of COPD, spirometry as a routine investigation has been implemented in primary care settings in many countries. $^{37-39}$

\section{Conclusion}

These results demonstrate that COPD, albeit in a mild form, was detected in one of every 10 tested patients. They also suggest that, with spirometry testing, patients with COPD could be detected in the earlier stages of the disease.

\section{Disclosure}

The authors report no conflicts of interest in this work.

\section{References}

1. Celli BR, MacNee W. ATS/ERS Task Force. Standards for the diagnosis and treatment of patients with COPD: A summary of the ATS/ERS position paper. Eur Respir J. 2004;23:932-946.

2. Calverley PMA, Georgopoulous D. Chronic obstructive pulmonary disease: Symptoms and signs. European Respiratory Monograph. 2006; 38:7-23.

3. Viegi G, Scognamiglio A, Baldacci S, Pistelli F, Carrozzi L. Epidemiology of chronic obstructive pulmonary disease (COPD). Respiration. 2001;68:4-19.

4. World Health Organization. Health statistics and health information systems: Burden of disease statistics. Available at: http://www.who. int/healthinfo/global_burden_disease/en/. Accessed on January 24, 2010.

5. Murray CJ, Lopez AD. Alternative projections of mortality and disability by cause 1990-2020: Global Burden of Disease Study. Lancet. 1997; 349:1498-1504.

6. Lundback B, Nystrom L, Rosenhall L, Stjernberg N. Obstructive lung disease in northern Sweden: Respiratory symptoms assessed in a postal survey. Eur Respir J. 1991;4:257-266.

7. Viegi G, Pedreschi M, Pistelli F, et al. Prevalence of airway obstruction in a general population: European Respiratory Society vs American Thoracic Society definition. Chest. 2000;117:339S-345S.

8. Mannino DM. Underdiagnosed chronic obstructive pulmonary disease in England: New country, same story. Thorax. 2006;61:1032-1034. 
9. Pena VS, Miravitlles M, Gabriel R, et al. Geographic variations in prevalence and underdiagnosis of COPD: Results of the IBERPOC multicentre epidemiological study. Chest. 2000;118:981-989.

10. Mannino DM, Gagnon RC, Petty TL, Lydick E. Obstructive lung disease and low lung function in adults in the United States: Data from the National Health and Nutrition Examination Survey, 1988-1994. Arch Intern Med. 2000;160:1683-1689.

11. Kim DS, Kim YS, Jung KS, et al; on behalf of the Korean Academy of Tuberculosis and Respiratory Diseases. Prevalence of chronic obstructive pulmonary disease in Korea: A population-based spirometry survey. Am J Respir Crit Care Med. 2005;172:842-847.

12. Talamo C, de Oca MM, Halbert R, et al; for the PLATINO team. Diagnostic labelling of COPD in five Latin American cities. Chest. 2007;131:60-67.

13. American Thoracic Society. Standardization of spirometry - 1994 update. Am J Respir Crit Care Med. 1995;152:1107-1136.

14. Pauwels RA, Buist AS, Calverley PMA, Jenkins CR, Hurd SS; on behalf of the GOLD Scientific Committee. Global strategy for the diagnosis, management and prevention of chronic obstructive pulmonary disease. NHLBI/WHO Global Initiative for Chronic Obstructive Pulmonary Disease (GOLD) Workshop summary. Am J Respir Crit Care Med. 2001;163:1256-1276

15. Fabbri LM, Hurd SS; for the GOLD Scientific Committee. Global strategy for the diagnosis, management and prevention of COPD: 2003 update. Eur Respir J. 2003;22:1-2.

16. Quanjer PH, Tammeling GJ, Cotes JE, et al. Lung volumes and forced ventilatory flows. Report working party. Standardization of lung function tests, European Community for Steel and Coal. Official statement of the European Respiratory Society. Eur Respir J. 1993;16 Suppl: $5-40$.

17. Halbert RJ, Natoli J, Gano A, Badamgarav E, Buist AS, Mannino DM. Global burden of COPD: Systematic review and meta-analysis. Eur Respir J. 2006;28:523-532.

18. Lange P, Groth S, Nyboe J, et al. Chronic obstructive lung disease in Copenhagen: Cross-sectional epidemiological aspects. J Intern Med. 1989;226:25-32.

19. Dickinson JA, Meaker M, Searle M, Ratcliffe G. Screening older patients for obstructive airways disease in a semi-rural practice. Thorax. 1999;54:501-505.

20. Isoaho R, Puolijoki H, Huhti E, Kivela SL, Laippala P, Tala E. Prevalence of chronic obstructive pulmonary disease in elderly Finns. Respir Med. 1994;88:571-580.

21. Von Hertzen L, Reunanen A, Impivaara O, Malkia E, Aromaa A. Airway obstruction in relation to symptoms in chronic respiratory disease: A nationally representative population study. Respir Med. 2000;94:356-363.

22. Gulsvik A. Prevalence and manifestations of obstructive lung disease in the city of Oslo. Scand J Respir Dis. 1979;60:286-296.

23. Bakke S, Baste V, Hanoa R, Gulsvik A. Prevalence of obstructive lung disease in a general population: Relation to occupational title and exposure to some airborne agents. Thorax. 1991;46:863-870.
24. Halbert RJ, Isonaka S, George D, Iqbal A. Interpreting COPD prevalence estimates. What is the true burden of disease. Chest. 2003; 123:1684-1692.

25. Zielinski J, Bednarek M; Know the Age of Your Lung Study Group. Early detection of COPD in a high-risk population using spirometry screening. Chest. 2001;119:731-736.

26. Van den Boom G, van Schayck CP, Rutten-van Molken MP, et al. Active detection of chronic obstructive pulmonary disease and asthma in the general population. Am J Respir Crit Care Med. 1998;158: 1730-1738.

27. Calverley PMA. COPD Early detection and intervention. Chest. 2000; 117 Suppl 2:365-371.

28. Ferguson GT, Enright PL, Buist AS, Higgins MW. Office spirometry for lung health assessment in adults: A consensus statement from the National Lung Health Education Program. Chest. 2000;117: 1146-1161.

29. Geijer RMM, Sachs APE, Hoes AW, Salome PL, Lammers JWJ, Verheij TJM. Prevalence of undetected persistent airflow obstruction in male smokers 40-65 years old. Fam Pract. 2005;22:485-489.

30. Fukuchi Y, Nishimura M, Ichinose M, et al. COPD in Japan: The Nippon COPD epidemiology study. Respirology. 2004;9:458-465.

31. Van Schayck CP, Loozen JMC, Wagena E, Akkermans RP, Wesseling GJ. Detecting patients at a high risk of developing chronic obstructive pulmonary disease in general practice: Cross sectional case finding study. BMJ. 2002;324:1370-1379.

32. Schirnhofer L, Lamprecht B, Vollmer MW, et al. COPD prevalence in Salzburg, Austria: Results from the Burden of Obstructive Lung Disease (BOLD) study. Chest. 2007;131:29-36.

33. Sin D, Stafinski T, Ying CNG, Bell RN, Jacobs P. The impact of chronic obstructive pulmonary disease on work loss in the United States. Am J Respir Crit Care Med. 2002;165:704-707.

34. Tzanakis N, Anagnostopoulou U, Filaditaki V, Christaki P, Siafakas N; on behalf of the COPD group of the Helenic Thoracic Society. Prevalence of COPD in Greece. Chest. 2004;125:892-900.

35. Doherty DE. Early detection and management of COPD. What you can do to reduce the impact of this disabling disease. Postgrad Med. 2002; $11: 41-44$.

36. Van den Boom G, Rutten-Molken MP, Tirimanna PR, van Schayck CP, van Folgering $H$, van Weel $C$. The association between health-related quality of life and consultation for respiratory symptoms: Results from the DIMCA programme. Eur Respir J. 1998;11:67-72.

37. Yawn BP, Enright PL, Lemanske RF, et al. Spirometry can be done in family physicians' offices and alters clinical decisions in management of asthma and COPD. Chest. 2007;132:1162-1168.

38. Takahashi T, Ichinose M, Inoue H, Shirato K, Hattori T, Takishima T. Underdiagnosis and undertreatment of COPD in primary care settings. Respirology. 2003;8:504-508.

39. Buffels J, Degryse J, Heyrman J, Decramer M. Office spirometry significantly improves early detection of COPD in general practice. The DIDASCO study. Chest. 2004;125:1394-1399.
International Journal of COPD

\section{Publish your work in this journal}

The International Journal of COPD is an international, peer-reviewed journal of therapeutics and pharmacology focusing on concise rapid reporting of clinical studies and reviews in COPD. Special focus is given to the pathophysiological processes underlying the disease, intervention programs, patient focused education, and self management protocols.

\section{Dovepress}

This journal is indexed on PubMed Central, MedLine and CAS. The manuscript management system is completely online and includes a very quick and fair peer-review system, which is all easy to use. Visit $\mathrm{http} / / / \mathrm{www}$.dovepress.com/testimonials.php to read real quotes from published authors. 